\title{
TRADUÇÃO E PARATRADUÇÃO DO ROMANCE CLOUD ATLAS (2004) DE DAVID MITCHELL NO BRASIL
}

\author{
TRANSLATION AND PARATRANSLATION OF \\ DAVID MITCHELL'S NOVEL \\ CLOUD ATLAS (2004) IN BRAZIL
}

\section{Yuri Jivago Amorim Caribé}

\section{RESUMO}

Esta pesquisa traz reflexões sobre paratextos relacionados ao romance inglês Cloud Atlas (2004), de David Mitchell e o processo de paratradução dessa obra, publicada no Brasil como Atlas de Nuvens (2016). O lançamento da tradução desse romance foi amplamente divulgado por importantes canais de comunicação, com apoio especial da crítica literária especializada. No entanto, a obra ainda é pouco lida e analisada no âmbito acadêmico. Assim, trabalhamos especialmente com o conceito de paratradução de Yuste Frías (2014 e 2015) para verificar o papel desempenhado pelos paratextos na edição final dessa obra traduzida. As conclusões apontam para um repensar do processo tradutório, diretamente influenciado pelo conceito de paratradução. Também nos levam a refletir sobre a participação dos paratextos como importante elemento de análise no processo de tradução literária de uma obra.

Palavras-chave: Atlas de Nuvens; tradução literária; paratradução.

\section{ABSTRACT}

This research brings some reflections on paratexts related to the English novel Cloud Atlas (2004), by David Mitchell and the process of translating this work, published in Brazil as Atlas de Nuvens (2016). The launch of the translation of this novel was widely publicized by important communication channels, with the special support from specialized literary critics. However, the translated novel is still not very known and read in Brazil, neither it is analyzed in the academic field. Thus, we worked especially with the concept of translation by Frías (2014 and 2015) to see what role the paratexts played in the final edition of that translated work. The conclusions lead us to a rethinking of the translation process, directly influenced by the concept of translation. They also lead us to reflect on the participation of paratexts as an important element of analysis in the process of literary translation. Keywords: Cloud Atlas; literary translation; paratranslation.

\footnotetext{
* Universidade Federal de Pernambuco, UFPE, Recife, PE, Brasil. yuricaribe@hotmail.com Orcid: http://orcid.org/0000-0002-4330-6654
} 


\section{INTRODUÇÃO}

Muitas vezes a recepção (pelo público leitor) de uma obra literária traduzida acontece em meio a uma série de incertezas por parte da editora que decidiu publicála, e isso pode ocorrer mesmo que o texto-fonte em língua estrangeira tenha sido um sucesso de público e de crítica no país onde essa obra foi originalmente lançada. Por isso, algumas editoras investem em pesquisas para conhecer os (pretensos) leitores de romances de ficção em tradução, por exemplo. Esse fato certamente ocorre no Brasil, país que abriga um público leitor bastante heterogêneo e que consome em larga escala literatura estrangeira (traduzida) em gêneros literários diversos, mas especialmente um público leitor de romances de ficção.

À proposito: essas diferenças entre o processo de lançamento de uma obra literária e de sua respectiva tradução literária (em outro país) foi objeto de estudo do teórico Itamar Even-Zohar (2012). Nesse estudo, Even-Zohar chama de sistemas literários os países envolvidos (o país de origem do texto-fonte e aqueles onde a tradução será publicada) e trabalha as relações que ocorrem entre eles a partir da publicação da tradução de uma obra literária. Inferimos então que cada um desses sistemas possui particularidades que podem alavancar algumas obras e provocar a desvalorização e até o apagamento de tantas outras. No caso das traduções de obras literárias, um erro frequente do país receptor é tentar mensurar comportamentos do público leitor com base nos leitores do texto-fonte.

Outro ponto a saber é o quão valorizada é a literatura traduzida nesse país em termos de status, algo também trabalhado por Even-Zohar no texto citado há pouco (EVEN-ZOHAR, 2012). Sabemos que, no caso do Brasil, é possível reforçar a tese de que a literatura estrangeira traduzida é bastante valorizada: uma simples conferência nos 100 livros mais vendidos da categoria Literatura e ficção do portal Amazon ${ }^{1}$ nos permite afirmar que ao menos $70 \%$ desses livros são romances estrangeiros traduzidos. Esse dado nos faz perceber que o leitor brasileiro valoriza romances das literaturas em língua estrangeira com reconhecido valor estético e fortuna crítica considerável, como o caso do romance contemporâneo Atlas de Nuvens (2016), do escritor inglês David Mitchell (1969-), lançado originalmente como Cloud Atlas em 2004 na Inglaterra.

Cloud Atlas foi publicado por uma importante editora e com ampla cobertura por parte da tríade a que nos referimos em estudo anterior (CARIBÉ, 2017), qual seja: a crítica literária especializada, a academia e o público leitor. Dizemos isso porque esse romance foi apresentado por diversos críticos importantes e em diversos portais

1. Acessado pelo website www.amazon.com.br. 
jornalísticos e literários do mundo, como no caso da elogiosa resenha feita pela premiada escritora inglesa A.S. Byatt (1936-) e publicada logo após o lançamento do livro em 2004 no The Guardian. O autor David Mitchell também foi entrevistado por diversos veículos da mídia eletrônica e audiovisual por ocasião do lançamento de Cloud Atlas, onde também encontramos muitas referências a essa obra. Some-se a isso os prêmios que recebeu: o British Book Awards (categoria ficção literária) em 2005 e o respeitado Richard \& Judy, vencendo como "livro do ano" também em 2005, além de várias nomeações. Foi adaptado para o cinema em $2012^{2}$ (A VIAGEM, 2012), rendendo ainda mais fôlego ao debate, que chegou também à academia: artigos, dissertações e teses foram publicadas internacionalmente ao longo desses 12 anos (2004-2020) do romance escrito por Mitchell. Bem recentemente (em 2019) Cloud Atlas figurou como um dos cem melhores livros do século XXI na lista anualmente publicada pelo The Guardian, consolidando o prestígio internacional desse romance e de seu escritor.

Outro fator relevante é a menção direta a Cloud Atlas em obra acadêmica de referência relacionada ao estudo da ficção contemporânea de autores britânicos: o trabalho de Richard Bradford intitulado The Novel Now (BRAFORD, 2007). Bradford diz que Mitchell, através de sua escrita, manipula acontecimentos e personagens de Cloud Atlas para conduzir o leitor a determinada interpretação. Para isso, dá pistas, como a marca de nascença que se repete em algumas personagens desse romance ao longo das várias narrativas, sem que possuam uma ligação aparente. Cloud Atlas também foi discutido na dissertação de mestrado de Beth Miller (2015), defendida na East Tennessee State University em Johnson (E.U.A.), e em alguns artigos publicados em importantes periódicos, como o de Brown (2016), publicado no Journal of Language, Literature and Culture.

Esse romance traz seis narrativas divididas em onze partes, que são apresentadas de forma muito interessante e que se relacionam. As seis primeiras partes seguem em sequência cronológica temporal, começando com os relatos de Adam Ewing anotados em um diário. Ewing é um tabelião estadunidense em viagem de navio pelas ilhas Chatham na Nova Zelândia em pleno século XIX, que escreve sobre sua relação com os índios morioris e também sobre suas experiências com outros personagens, o que leva essa personagem a refletir sobre questões como a da escravidão. Em seguida, conhecemos a (breve) vida de Robert Frobisher, jovem músico que se corresponde com seu amante Rufus Sixmith (um cientista) no ano de 1931 e conta sua experiência de trabalho como assistente de Ayrs, um conhecido e já idoso músico. Frobisher relata a Sixmith através dessas cartas (outro formato do

2. O lançamento no Brasil aconteceu somente em 2013. 
romance) o processo de criação do Sexteto Atlas de Nuvens ${ }^{3}$, uma composição musical que se torna sua grande obsessão e que dá nome à obra. Sixmith aparece de fato na terceira história e já mais velho. A história se passa nos anos 1970 na Califórnia (E.U.A.), onde encontramos Sixmith envolvido em uma investigação, juntamente com a jornalista Luisa Rey sobre o caso de uma usina nuclear, o que nos lembra um romance policial. Essa investigação torna-se o centro da quarta história, ambientada nos anos 2000 e que será lida pelo editor inglês Timothy Cavendish em um asilo. As últimas duas narrativas da primeira metade da obra acontecem em ambientes de um futuro distante, conforme explicaremos a seguir. A quinta narrativa nos apresenta a personagem Sonmi $451 \mathrm{em} 2144$, uma entidade artificial (porém com aparência idêntica a dos seres humanos) criada para trabalhar em uma lanchonete e que se torna líder de uma rebelião. A sexta narrativa futurista traz a história de Zachry (no ano de 2321), um habitante das ilhas do Pacífico que tenta sobreviver em um contexto de selvageria após um desastre nuclear.

Finda a primeira parte (subdividida em seis narrativas), percebemos que as cinco primeiras histórias (já que a sexta narrativa é totalmente concluída) são retomadas em ordem inversa e concluídas uma a uma. Nos parece que a proposta de Mitchell é construir um romance em "camadas" ou com um sequenciamento de histórias que contém outras histórias, todas apresentadas em linguagem dinâmica. Aliás, outra marca dessa obra são as linguagens pensadas por Mitchell e que são particulares à cada época ou à cada personagem. Cloud Atlas também mescla gêneros literários diversos em sua composição: diários, cartas e até a proposta de um romance policial, dentre outros.

Sabemos ainda que Cloud Atlas foi traduzido e publicado em vários países do mundo, sendo que no Brasil isso ocorreu muito tardiamente (apenas em 2016). Fazemos essa constatação diante do cenário que normalmente se apresenta no mercado editorial brasileiro de obras das literaturas estrangeiras (e seus autores) que já gozam de certo prestígio crítico e/ou acadêmico em seus países de origem, conforme nos lembra Even-Zohar (2012): costumam ser traduzidas e publicadas poucos meses após o lançamento do texto-fonte, como nos lembra o caso do romance As Horas ${ }^{4}$ de Michael Cunningham (1952-), traduzido por Beth Vieira e

3. A resenha recentemente publicada por João Paulo Silva (SILVA, 2020) no Jornal Mais Minas nos informa que Cloud Atlas é o nome de uma música composta pelo japonês Toshi Ichiyanagi, primeiro marido de Yoko Ono (que por sua vez é viúva do cantor e compositor John Lennon), e que esse nome possivelmente inspirou o título da obra de Mitchell. O título Atlas de Nuvens também é homônimo a um guia usado na metereologia para classificar os tipos de nuvens.

4. A tese do autor (CARIBÉ, 2015) trabalha o romance The Hours e os elementos adaptados por Cunningham de obras da escritora inglesa Virginia Woolf. 
lançado no Brasil em1999, apenas um ano após a publicação do texto-fonte (The Hours, 1998). Um caso mais recente é o do lançamento do intrigante romance Enclausurados, pelo britânico Ian McEwan (1948-), publicado no Brasil apenas alguns meses após o lançamento do texto-fonte na Inglaterra (MCEWAN, 2016). Casos como esse ocorrem especialmente quando a mídia divulga mensagens que chamamos de spoilers (que já são epitextos das obras) sobre o novo romance criado por um já reconhecido escritor (como McEwan) em campanhas publicitárias meticulosamente calculadas. Nesse caso, as próximas obras desse escritor passam a ser aguardas com certa ansiedade pelo público leitor. A mesma prerrogativa se aplica às chamadas sagas: o novo volume é aguardado com certa ansiedade pelo público-leitor, já que o anterior havia sido recebido com sucesso.

No entanto, vale ressaltar que nesse processo tudo é cuidadosamente planejado. No Brasil, profissionais da editora interessada em publicar determinada obra literária em tradução costumam fazer pesquisas sobre o comportamento do leitor do país de chegada, o momento sócio-histórico-político e econômico desse país, etc. Costumam também usar diversos parâmetros: a publicação de resenhas em jornais internacionais reconhecidos, o recebimento de prêmios, se a obra foi adaptada para o cinema ou para outro formato, se foi comentada nas redes sociais e sites dedicados a literatura e, finalmente, se registrou bons números nas vendas dos exemplares físicos e/ou $e$-books. Todos esses são fatores que aceleram o processo de tradução e publicação em outros países/línguas/sistemas literários, visto que dão certa segurança à editora que publica a tradução. Assim, essas informações podem levar uma obra de reconhecido valor estético em seu país de origem a ser publicada em tradução no Brasil em um curto intervalo de tempo após o lançamento do textofonte.

Esses parâmetros observados pelas editoras brasileiras para imaginar a possível recepção dos leitores ao texto traduzido no país de chegada (nesse caso o Brasil) nos levam a refletir sobre a ideia de transculturalidade, conceito trabalhado por Benessaieh (2010), dentro outros pesquisadores da contemporaneidade. Como trabalhar com esses parâmetros se tratamos de dois sistemas literários distintos (o inglês e o brasileiro)? Como se as culturas (e os produtos culturais) desses dois países também parecem distintos? A ideia de transculturalidade "nos convida a considerar a mistura de culturas presumivelmente distintas e as linhas borradas entre elas" (BENESSAIEH, 2010, p. 11), pensamento diametralmente oposto à uma visão de cultura como sistema "fechado" ou estável. Há que se considerar a era dinâmica em que nos encontramos agora, além do advento das comunicações

5. Ver trabalho do autor sobre essa obra (CARIBÉ, 2019). 
e das tecnologias midiáticas, os crescentes fluxos migratórios e de mobilidade, e o maior acesso a produtos culturais do mundo todo. Esses fatores apontam para uma dinâmica de maior e mais complexa proximidade (e adversidade) cultural entre os países do mundo, inclusive entre a Inglaterra e o Brasil. Assim, essas são importantes características da globalização que conectam as culturas do mundo todo (BENESSAIEH, 2010, p. 14).

Podemos, então, afirmar que as culturas desses dois países (a Inglaterra e o Brasil) se intercomunicam mais que antes e, assim, se inter-relacionam. Os parâmetros do lançamento de Clould Atlas em 2004 na Inglaterra poderiam ser utilizados, desde que as particularidades do leitores brasileiros não fossem negligenciadas pelas editoras, e assim acreditamos ter ocorrido. $\mathrm{O}$ processo de publicação da tradução desse romance seguiu lentamente até 2016, conforme dissemos antes. A editora responsável parece ter feito um amplo trabalho de pesquisa, inclusive envolvendo os paratextos de Clould Atlas. Na versão em livro físico da tradução publicada no Brasil um paratexto se destaca: a luva ${ }^{6}$ (também chamada de box ou capa em tie-in) em si, além do design de sua capa, contracapa e demais partes. Trata-se de um novo paratexto que agregou valor à obra traduzida.

$\mathrm{O}$ processo de tradução dos textos que, no caso de um romance, por exemplo, o circundam, foi chamado de paratradução pelos pesquisadores do Grupo Tradução e Paratradução da Universidade de Vigo na Espanha, em especial pelo Professsor Yuste Frías (YUSTE FRÍAS, 2014 e 2015). Os paratextos deveriam ser traduzidos e acompanhados de perto pelo tradutor da obra literária antes e durante o processo de lançamento de uma tradução. De acordo com esse conceito, é importante estudar as "produções verbais, icônicas, verbo-icônicas e materiais que circundam, envolvem, acompanham, introduzem, apresentam e ampliam o texto traduzido" (YUSTE FRÍAS, 2015, p. 322). É o que procuramos fazer neste artigo que ora apresentamos.

Assim, elaboramos um breve estudo sobre a recepção do romance Cloud Atlas com foco na questão dos paratextos. Sabemos que essa obra foi publicada no Brasil por uma importante editora (Companhia das Letras) com o título Atlas de Nuvens (MITCHELL, 2016) e com tradução do reconhecido Paulo Henriques Britto (1951-). Britto inclusive traduziu diversas obras em poesia e prosa das Literaturas de Língua Inglesa da contemporaneidade, dentre elas o romance Reparação (MCEWAN, 2001), de Ian McEwan, escritor já citado neste trabalho. Destarte, analisar a questão da tradução desses paratextos (dando origem a novos paratextos) para a obra traduzida e publicada no Brasil nos pareceu relevante. Propomos, então,

6. Uma espécie de caixa para o livro físico, comum em edições mais caprichadas nos aspectos visuais. 
uma reflexão sobre o espaço paratextual (NOUSS, 2012, p. 26) do romance Cloud Atlas e de sua tradução (com foco na questão das capas), lugar privilegiado para que a tradução seja pensada.

No que diz respeito a metodologia, trabalhamos para construir ensaios em nível empírico, já que apresentamos elementos paratextuais não verbais de Atlas de Nuvens (YUSTE FRÍAS, 2014, p. 30). Tomamos como base principal para essa discussão o importante conceito de paratradução diretamente trabalhado por Yuste Frías (2014 e 2015), além de outras referências relacionadas aos Estudos de Tradução, com foco em questões relacionadas à tradução literária. Citamos ainda resenhas sobre esse romance e sua tradução, além de pesquisas acadêmicas que tenham a obra (texto-fonte ou sua respectiva tradução) como objeto de estudo. Também vamos nos referir ao trabalho do tradutor Paulo Henriques Britto e da equipe editorial responsável pela edição em língua portuguesa. Por fim, discutimos algumas estratégias editoriais visuais, chamadas de unidades verbais icônicas, como a luva da edição brasileira no formato de livro físico, a presença de fotos, dentre outros elementos paratraduzidos.

\section{FORTUNA CRÍTICA SOBRE A OBRA E SUA TRADUÇÃO}

Conforme adiantamos, Cloud Atlas (2004) foi bastante divulgado e recomendado no cenário internacional pela tríade formada pela crítica literária especializada (escritores, críticos de literatura e tradutores reconhecidos, que publicam resenhas em importantes jornais e também em blogs e outros meios), pela academia e pelo grande público ${ }^{7}$. Ressaltamos ainda o papel dos booktubers ${ }^{8}$ e de outros influenciadores digitais na formação do reconhecimento público ao valor estético dessa obra, além dos importantes prêmios literários e indicações que Cloud Atlas recebeu fora do Brasil. Inclusive recentemente o empresário Bill Gates indicou esse romance para leitura durante o período de quarentena vivido por povos do mundo todo em decorrência da pandemia causada pelo novo coronavírus, conforme relata Diáz (2020) em matéria no site da Revista Forbes. Essas referências nos falam sobre a relevância e permanência dessa obra, especialmente em debates sobre o futuro da humanidade.

7. A edição mais recente do original indica na capa que a obra alcançou o status de best-seller segundo o New York Times.

8. Youtubers que comentam obras literárias recém-lançadas em seus canais no YouTube e dão dicas para leitores baseadas em suas experiências. 
No Brasil, Atlas de Nuvens foi pauta de resenhas feitas por importantes jornalistas/críticos/escritores como Klein (KLEIN, 2016) - publicada no Jornal O Globo - e Carlos Graieb - publicada na Folba de S. Paulo -, inclusive elogiando a tradução feita por Britto (GRAIEB, 2016). Também foi amplamente indicado e comentado por booktubers em plataformas da internet e nas redes sociais. Todavia, encontramos poucos estudos acadêmicos realizados no Brasil e que tenham relação com esse romance.

Em levantamento bibliográfico no Catálogo de teses e dissertações da CAPES (CAPES, 2020) de forma pontual para a realização deste trabalho, localizamos apenas a dissertação de mestrado de Davi Souza (SOUZA, 2018), recentemente defendida no Programa de Pós-Graduação em Letras do Instituto de Biociências, Letras e Ciências Exatas da Universidade Estadual Paulista "Júlio de Mesquita Filho", Campus de São José do Rio Preto (São Paulo, Brasil). Souza trabalha o tema da subalternidade no romance Atlas de Nuvens através das relações estabelecidas entre alguns personagens, utilizando arcabouço teórico do campo de pesquisa conhecido como Estudos Subalternos. Pretende assim provar que esse romance dá voz a classes de pessoas subalternas, ao mesmo tempo em que apresenta fortes críticas a sociedade hegemônica do qual faz parte.

Também localizamos o artigo de Valéria Pereira (PEREIRA, 2016) publicado na revista Em Tese da Universidade Federal de Minas Gerais (UFMG) e que aponta Atlas de Nuvens como um slipstream, categoria literária caracterizada pelas temáticas futurísticas e pela estranheza que costuma causar nos leitores. Dessa forma, o trabalho de Pereira (2016) se configura em um ensaio histórico e conceitual bastante coerente sobre algumas leituras teóricas relacionadas à ficção científica e a narrativas literárias que apresentam temáticas típicas desse gênero. Atlas de Nuvens é classificado pela autora como um slipstream pelas diferenças em sua estrutura narrativa e pelos elementos científico-funcionais percebidos em duas narrativas que se passam futuro.

Percebemos então a presença de muitos aspectos que, em tese, favoreceriam a boa recepção dessa obra em países que consomem literatura traduzida com bastante frequência, como é o caso do Brasil. Diante dessas informações, acreditamos que esta pesquisa poderá motivar outros trabalhos acadêmicos sobre esse importante romance. 


\section{PARATEXTOS DO ROMANCE "ATLAS DE NUVENS"}

Passamos, então, à questão dos paratextos encontrados no texto-fonte. Depois disso, exibiremos uma descrição sobre as traduções desses paratextos. A edição original de 2004 é atualmente comercializada em várias versões, inclusive em audiobook, o que demonstra certa relação dessa obra com a tecnologia e o futuro. Apresentaremos as capas das quatro edições originais, sabendo que as primeiras versões em livro físico (Figuras 2 e 3 ) foram possivelmente consultadas pela editora brasileira durante o processo de tradução. Nosso objetivo é estabelecer um possível diálogo com a capa adotada na tradução publicada no Brasil, visto que capas (e toda a iconografia utilizada em sua composição) são importantes paratextos que demandam cuidado por parte das editoras durante o processo de tradução editorial de uma obra reconhecida como Cloud Atlas.

A figura a seguir (Figura 1) traz a imagem do romance original comercializado em formato digital (ebook kindle). Trata-se de uma produção verbo-icônica interessante: uma máquina de escrever de onde parecem sair textos e nuvens que nos remetem ao título da obra (Atlas de Nuvens), formando uma espécie de furacão, conforme apresentada a seguir:

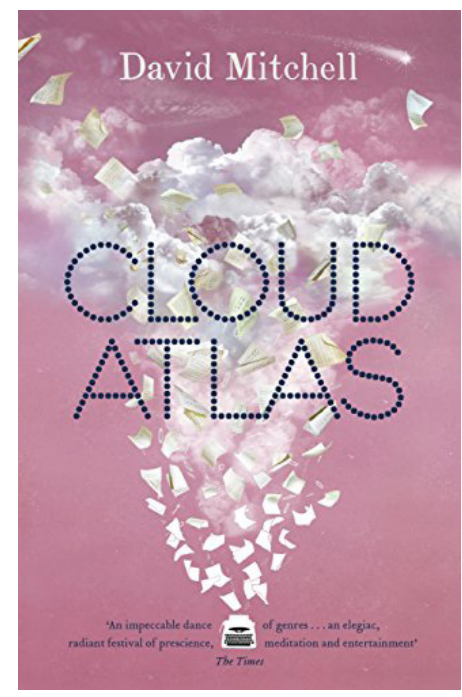

Figura 1. Fonte: Website da Amazon. Disponível em: <https://www.amazon.com.br/Cloud-Atlas-English-David-Mitchell-ebook/dp/B002VHI8J0/ref=tmm kin swatch 0 ? encoding=UT F8\&qid=1595193440\&sr=1-1>. 
A máquina de escrever da Figura 1 faz referência a personagem Luisa Rey, jornalista que escreve seu romance policial nos anos de 1970. A imagem também nos leva a pensar sobre os aspectos metaficcionais desse romance, já que várias personagens o "escrevem" e de formas diferentes (uma escreve um diário, outra escreve cartas, dentre outros formatos). A personagem Timothy Cavendish, por exemplo, é um editor de livros que passou a vida cercado pelo ofício da escrita e que na velhice foi morar em um asilo e lá escreve suas memórias. Assim, percebo que a escrita é pauta desse romance e essa capa celebra esse aspecto. Por fim, sobrepostas a essas imagens estão o nome e sobrenome do autor (centralizado no alto da capa), seguindo do título (Cloud Atlas) e de um trecho de uma resenha (positiva) de um importante jornal internacional sobre essa obra, tudo isso em um fundo cor de rosa.

A próxima capa do original Cloud Atlas (Figura 2) que exibiremos se refere ao formato em livro físico, mas que já foi utilizada na versão digital. Foi comercializada em edição de luxo em capa dura e vendida a um preço mais elevado.

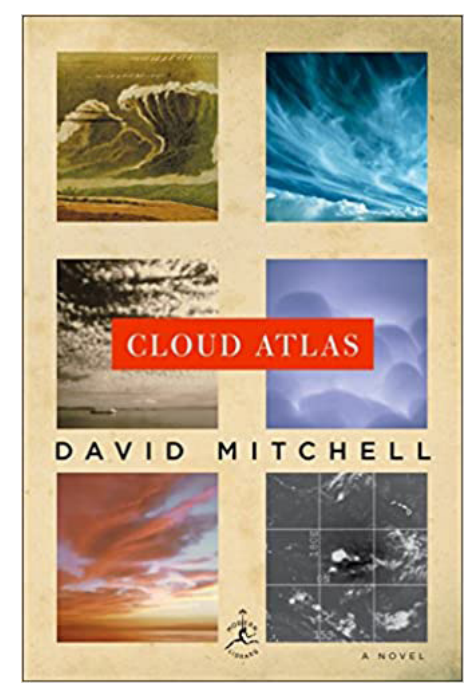

Figura 2. Fonte: Website da Amazon. Disponível em: $<$ https://www.amazon.com.br/Cloud-Atlas-David-Mitchell/dp/081299471X/ref=tmm hrd swatch 0? encoding=UTF8\&qid=1595 $193440 \& s r=1-1>$.

O design apresentado mostra uma composição com seis fotografias que retratam diferentes cenários de um céu com nuvens. Notamos uma composição de cores e certa tendência a retratar o entardecer. O título aparece centralizado nessa composição e bem destacado em um fundo vermelho. Logo abaixo do título, aparecem nome e sobrenome do autor David Mitchell. As nuvens nos remetem 
ao título e a várias passagens em que o céu e as nuvens são citados. Há outros elementos verbais na capa que não interferem em nossa análise.

As próximas imagens se referem a duas edições em capa comum. A Figura 3 traz uma ilustração bem simples, conforme apresentaremos a seguir:

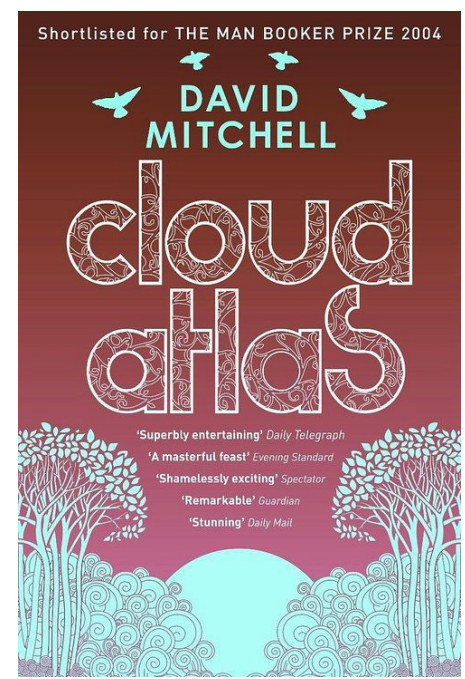

Figura 3. Fonte: Website Pinterest. Disponível em: $<$ https://br.pinterest.com/pin/47034475483 4883428/>.

A ilustração dessa terceira capa remete ao cenário onde vive a personagem Zachry: uma ilha do Pacífico em um futuro pós-apocalíptico em que a vida humana foi quase que completamente destruída (sobraram poucos humanos). Dessa forma, o cenário naquela narrativa é de florestas com animais selvagens. O fundo da imagem é vermelho e as ilustrações principais estão em azul. Destacamos um sol no entardecer (ocupando a parte central inferior da capa), copas de árvores nas laterais e pássaros na parte superior. O título da obra (com desenhos em cada letra) e o nome e sobrenome do autor aparecem bem destacados e em posição central nesta capa. Também há trechos de resenhas elogiosas ao romance e o fato de ter sido indicada ao prêmio The Man Booker Prize em 2004. Apresenta peritextos icônicos (YUSTE FRÍAS, 2014, p. 36) mais simples, sendo, portanto, menos atraente que as capas retratadas nas figuras 1 e 2 .

Agora apresentamos a quarta capa do romance original (Figura 4): 


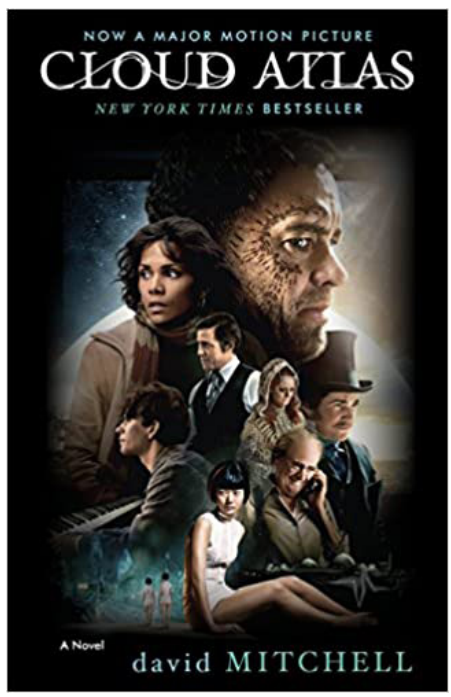

Figura 4. Fonte: Website da Amazon. Disponível em: < https://www.amazon.com.br/Cloud-Atlas-David-Mitchell/dp/0812984412/ref=tmm pap swatch 0? encoding=UTF8\&qid=1595 $193440 \& s r=1-1>$.

Edições mais recentes, como já é de praxe no mercado editorial literário, utilizam imagens da adaptação fílmica (A VIAGEM, 2012) na capa da obra, como podemos ver na Figura 4 (edição em capa simples). Assim, o processo de composição dessa capa se baseia em imagens de importantes personagens do romance e do filme, com destaque para Zachry (interpretado por Tom Hanks) e Luisa Rey (por Halle Berry). Também cita o fato de o romance ter sido adaptado para o cinema e de ter sido classificado pelo New York Times como best-seller.

$\mathrm{Na}$ parte interna do livro original em inglês percebemos que as quatro edições são idênticas em paratextos verbais que antecedem o início do romance: duas páginas com trechos de resenhas, outra com indicações de mais livros do autor, uma página com uma dedicatória, outra com ficha catalográfica e mais uma com agradecimentos. Temos ainda um sumário criado por Mitchell, que nos parece essencial à leitura dessa obra, dada a sua complexidade, extensão, vozes e as interpelações que as narrativas estabelecem entre si.

$\mathrm{Na}$ tradução desses paratextos (edição brasileira), percebemos que também houve uma preocupação por parte da editora com a questão da apresentação visual da obra. Yuste Frías (2014, p. 34) inclusive trata dessa relação ao perceber a estrutura indissolúvel entre texto e imagem, na qual nem o texto tem uma função subordinada, nem a imagem uma função apenas ilustrativa. Ambos devem ser coordenados e 
funcionar em constante diálogo. Afirma ainda que "a concepção e a regulamentação do sentido em qualquer texto podem variar conforme seus paratextos" (YUSTE FRÍAS, 2014, p. 27). Conclui falando da importância de reconhecer esses paratextos no texto-fonte e procurar equivalentes que façam sentido na edição traduzida, já que cada paratexto "constrói o palco, o ambiente, a atmosfera em que o texto será lido e traduzido" (YUSTE FRÍAS, 2015, p. 324).

Aliás, temos pouca informação sobre o processo editorial de tradução dessa obra. Britto até concedeu uma entrevista para a crítica e tradutora Camila Von Holdefer no mesmo ano em que a obra foi lançada (2016), mas se ateve a comentar brevemente sobre os desafios linguísticos que encontrou para manter a coerência das diversas linguagens e registros de fala de alguns personagens em épocas tão distintas (passado e futuro) dentro de cada narrativa, além de classificar o livro como engenhoso e criativo. Também confessou que a tradução levou quinze meses para ficar pronta. Pela entrevista, pareceu que Britto não acompanhou a tradução dos paratextos visuais (como o design da capa), contrariando a indicação feita por Yuste Frías $(2015$, p. 322).

De toda forma, o resultado foi surpreendente. No Brasil, o romance de Mitchell no formato de livro físico foi publicado exclusivamente em edição de luxo com acabamento em brochura, acompanhada de uma luva cheia de fotografias relacionadas a elementos diversos das narrativas de Atlas de Nuvens, conforme exibiremos nas figuras a seguir (Figuras 5, 6 e 7). Vale ressaltar que o projeto visual adotado para os formatos digital e físico foi o mesmo para a capa: uma composição de imagens justapostas que remetem a diversos momentos das narrativas de Atlas de Nuvens. O título aparece centralizado em letras vermelhas em caixa alta sobrepostas às imagens e em destaque. Nome e sobrenome do autor aparecem a seguir. A lombada, contracapa e demais partes da luva seguem o mesmo padrão da capa, mas em continuidade, ou seja, exibem outras imagens. 


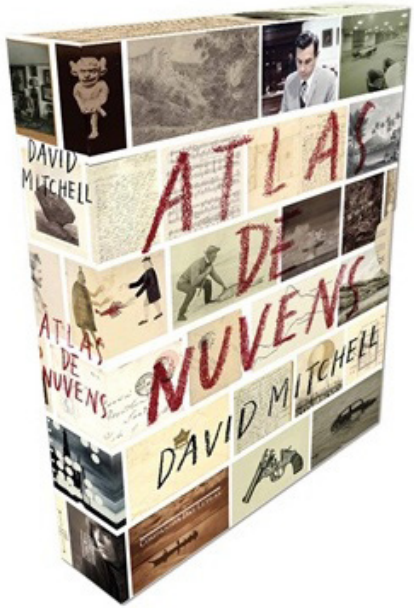

Figura 5. Fonte: Website do Jornal Mais Minas. Disponível em: $<$ https://maisminas.org/entretenimento/literatura/2018/10/20/atlas-de-nuvens-caminhos-cruzados $>$.

A próxima imagem (Figura 6) mostra a "verdadeira" capa do livro encaixada na luva exibida anteriormente. A capa e a contracapa são bem simples e não apresentam título ou qualquer outra informação verbal, apenas anotações do músico Frobisher em pentagramas musicais utilizados na composição do sexteto Atlas de Nuvens. Essa composição visual da capa e da contracapa sugere uma metáfora dessa obra literária como uma música.

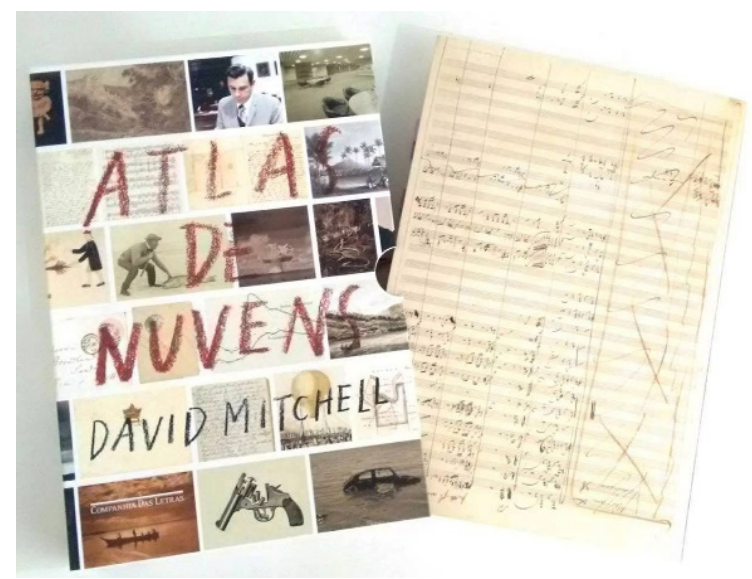

Figura 6. Fonte: Website da Revista Pólen. Disponível em: $<$ https://revistapolen.com/atlas-de-nuvens-david-mitchell/>. 
A contracapa (Figura 7) destaca ainda a tradução da obra por Paulo Henriques Britto, o que aponta para uma apresentação também pela figura do tradutor, possivelmente conhecido por muitos leitores brasileiros.

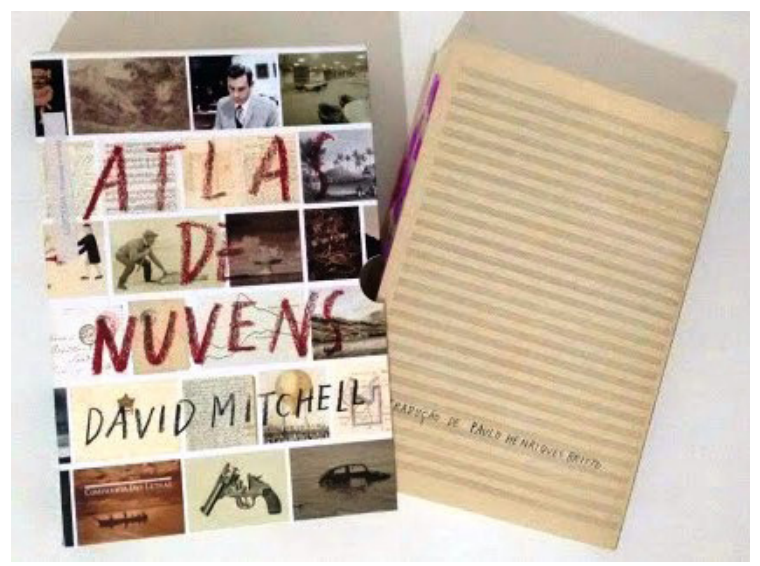

Figura 7. Fonte: Website I love my books. Disponível em: <https://www.lovemybookss. com/2017/02/resenha-atlas-de-nuvens.html>.

A seguir (Figura 8), apresentamos a capa da edição comercializada no formato digital (ebook kindle), que apresenta o mesmo design da edição em livro físico.

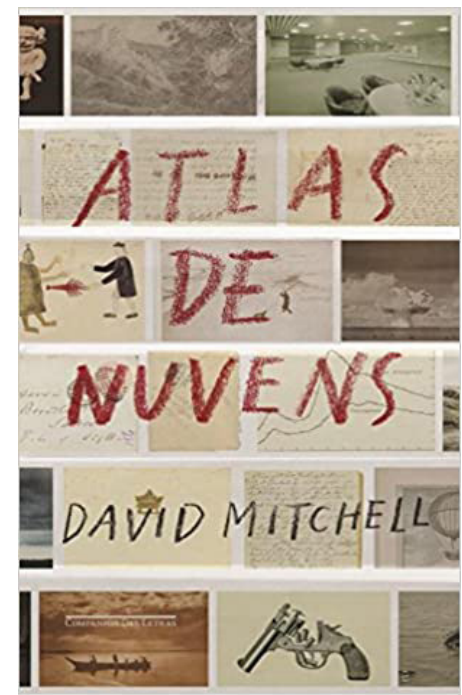

Figura 8. Fonte: Website da Amazon. Disponível em: $<$ https://www.amazon.com.br/Atlas-nuvens-David-Mitchell/dp/8535927581/ref=tmm pap swatch 0? encoding=UTF8\&qid=15951 96205\&sr=1-1>. 
A edição brasileira em livro físico é caprichada em termos de design, portanto foi vendida a um preço mais elevado (atualmente a versão em livro digital é a mais comercializada e seu preço é mais acessível). Ainda assim, o livro físico estava esgotado em vários websites de livros (como no portal Amazon já citado) até a conclusão desta pesquisa (2020).

As fotos da luva nos remetem a várias passagens do livro, como a imagem de um revólver, provavelmente fazendo alusão aos crimes que aparecem em diversos momentos das narrativas, como a morte do personagem Rufus Sixsmith. Destacamos ainda a imagem de um fusca afundando na água, que remete à morte acidental da jornalista Luisa Rey, envolvida em uma investigação sobre a existência de uma usina nuclear. Há inclusive outra foto nessa capa em que se pode observar uma explosão nuclear, que (apesar de não ser dita textualmente no romance) também pode indicar um motivo que levou a humanidade ao extermínio e, portanto, ao futuro pósapocalíptico em que vive o personagem Zachry em uma das narrativas.

Também encontramos fotos de anotações, de uma carta e de um envelope de carta, o que traz a ideia das experimentações do autor com gêneros literários diversos e de como a escrita é pauta recorrente dentro desse romance. Sentimos pela ausência de imagens que lembrassem a leitura distópica que é a narrativa de Sonmi 451 , ambientada em um mundo futurista. As imagens da luva concentramse em narrativas do passado e até do presente, mas negligenciam as narrativas futuristas de Atlas de Nuvens. A disposição aparentemente confusa e desconexa dessas fotos na luva (e que fazem referências a várias épocas e temas) se organiza na capa interna: a partitura do sexteto Atlas de Nuvens. Isso nos faz acreditar que, à primeira vista, o romance é composto por seis narrativas diferentes entre si. No entanto, ao tirar o livro da luva, nos deparamos com a capa e contracapa simples que representam uma (única) música, e que dá nome à obra. São sim seis instrumentos (por isso um sexteto), mas apenas uma composição musical. São seis narrativas, mas que compõem um único romance.

Essas fotos e respectivas alusões a diversos momentos do romance podem ser vistas de forma mais clara em um vídeo de apresentação da obra, que foi disponibilizado pela editora em seu canal no YouTube (PÁGINA DA COMPANHIA DAS LETRAS NO YOUTUBE, 2016). Esse vídeo mostra como esses elementos nortearam a composição do design da capa da luva e da edição digital, trabalho realizado por Elisa von Randow, importante agente paratradutora nesse contexto (YUSTE FRÍAS, 2015, p. 324). Assim, o vídeo constrói um epitexto audiovisual completo em torno do romance Atlas de Nuvens e que, não por acaso, se encontra disponível na rede mundial de computadores. 
Internamente na edição brasileira encontramos uma orelha, destinada a apresentação do autor Mitchell, mas sem identificação. Na sequência, encontramos uma página com dedicatória e outra com agradecimentos de Mitchell, tudo traduzido por Britto. Notamos a ausência de um prefácio na obra traduzida, importante paratexto e espaço comumente concedido ao tradutor para que se coloque como agente responsável pela concretização daquela versão. $\mathrm{O}$ sequenciamento interno das páginas da edição em formato digital é basicamente o mesmo do texto físico. A única exceção é a ausência do texto da orelha: a apresentação do autor é feita somente na última página através de uma foto e de um breve resumo sobre a carreira de Mitchell.

\section{CONSIDERAÇÕES FINAIS}

Percebemos que os elementos que citamos e comentamos participam juntamente com o texto traduzido "na construção do sentido do texto finalmente editado e publicado" (YUSTE FRÍAS, 2014, p. 27). Porém, essa obra ainda não alcançou um grande público leitor no Brasil, tampouco tornou-se objeto de interesse acadêmico, a despeito dos paratextos traduzidos e até do lançamento de uma adaptação em 2012. A editora que publicou a tradução no Brasil parece ter se cercado de muitos cuidados relacionados ao conhecimento e interpretação dos paratextos de partida (YUSTE FRÍAS, 2015, p. 344), que segundo Yuste Frías são "essenciais para apresentar e introduzir textos no mundo editorial" (FRÍAS, 2015, p. 334). Assim, respeitou o original, que se torna outro "a partir do momento em que é traduzido, uma vez que não pode ser reproduzido de forma idêntica" (NOUSS, 2012, p. 30). Entendemos como natural que a tradução dos textos e também dos paratextos de Cloud Atlas traga "toda uma gama de outras características, como novas linguagens (poéticas), ou técnicas e padrões composicionais" (EVEN-ZOHAR, 2012, p. 04). Ainda assim, afirmamos que esse romance circula pouco (desde seu lançamento em 2016) tanto entre leitores, quanto entre pesquisadores.

A editora recriou paratextos do original, ressaltando a importância da paratradução como atividade intimamente associada ao mundo editorial, visto que funciona como parâmetro para as diferentes fases do controle de qualidade das traduções editadas (YUSTE FRÍAS, 2015, p. 334). Das primeiras capas, restou apenas a ideia de quadrados justapostos com fotos, mas não de nuvens.

Aliás, o motivo das nuvens foi totalmente superado por razões desconhecidas. Dentro das narrativas desse romance, a palavra nuvens aparece tanto nas menções ao Sexteto Atlas de Nuvens (composição musical de Frobisher), quanto em comentários 
sobre o céu poluído na história de Sonmi 451 , que se passa em um mundo futuro, onde a poluição tomou conta de tudo. Concluímos que talvez o problema não tenha sido exatamente a não inspiração no motivo das nuvens (das capas originais), mas certa negligencia no tocante ao perfil do pretenso público leitor no Brasil e suas particularidades e preferências. Por exemplo: é bem possível que a narrativa futurista de Sonmi 451 (que se passa em um mundo bastante avançado em termos de tecnologia, apesar da poluição) pudesse ser mais atrativa ao leitor brasileiro, que conta com muitos adeptos dos romances de ficção científica e outras categorias relacionadas. A editora poderia, então, ter explorado essa narrativa na capa, importante paratexto e elemento de atração e apresentação da obra.

Pensando na questão da transculturalidade abordada no início desta pesquisa, inferimos que a capa talvez não tenha se afinado com o leitor brasileiro, o que demonstra a existência de algumas diferenças entre leitores do texto-fonte e da obra traduzida. A transculturalidade nos leva ao perigoso desejo de viver e entender a alteridade e a sedução de estabelecer um senso de entendimento que possa reduzir a distância do que percebemos como diferente (BENESSAIEH, 2010, p. 30).

Por fim, essa obra e seu autor permanecem pouco conhecidas pelo leitor brasileiro adepto a romances desse tipo. Talvez pela tradução recente, talvez pelos paratextos. De toda forma, refletimos sobre o processo de tradução dos paratextos de uma obra literária que goza de prestígio e reconhecimento internacional e sobre o que ocorre às margens desse processo (YUSTE FRÍAS, 2015, p. 331), sendo essa a proposta principal do conceito de paratradução.

\section{REFERÊNCIAS}

BENESSAIEH, A. (2010). Multiculturalism, Interculturality, Transculturality. In: BENESSAIEH, A. (ed.). Amériques transculturelles - Transcultural Americas. Ottawa (Canadá): University of Ottawa Press, pp. 11-38.

ÇAM, D. (2020). Bill Gates indica 5 livros para a quarentena. Revista Forbes. Disponível em: <https://forbes.com.br/colunas/2020/05/bill-gates-indica-5-livros-para-aquarentena/\#foto2 $>$. Acesso em: 12 jun. 2020.

PÁGINA DA COMPANHIA DAS LETRAS NO YOUTUBE. (2016). A capa de Atlas de Nuvens. Disponível em: <https://www.youtube.com/watch?v=1ol4QLUA9Hs >. Acesso em: 12 jun. 2020. 
A VIAGEM. (2012). Dirigido e roteirizado por Lana Wachowski, Lili Wachowski e Tom Tykwer. E.U.A.: Warner Bros. Pictures. 1 vídeo (176 min). Disponível em: <https://www.justwatch.com/br/filme/a-viagem>. Acesso em: 28 fev. 2020.

BRADFORD, R. (2007). The Novel Now: Contemporary British Fiction. Malden (E.U.A.): Blackwell Publishing.

BROWN, K. (2016). Finding Stories to Tell: Metafiction and Narrative in David Mitchell's Cloud Atlas. Journal of Language, Literature and Culture, v. 63, n. 1, pp. 77-90.

BYATT, A. S. (2004). Overlapping lives. Jornal The Guardian. Sessão Books. 06. mar. 2004. Disponível em: < https://www.theguardian.com/books/2004/mar/06/fiction. asbyatt $>$. Acesso em: 28 fev. 2020.

CAPES. (2020). Coordenação de Aperfeiçoamento de Pessoal de Nível Superior. Serviços: Catálogo de teses e dissertações. Disponível em: < https://catalogodeteses.capes. gov.br/catalogo-teses/\#!/>. Acesso em: 28 fev. 2020.

CUNNINGHAM, M. (1998). As Horas, trad. Beth Vieira. São Paulo: Companhia das Letras, 1999.

CARIBÉ, Y. J. A. (2015). Tradução, Adaptação e Reescrita da Obra de Virginia Woolf por Michael Cunningham em The Hours (1998). São Paulo. Tese (Doutorado em Letras). Faculdade de Filosofia, Letras e Ciências Humanas, Universidade de São Paulo.

CARIBÉ, Y. J. A. (2017). Formando novos cânones literários: a publicação de autores contemporâneos em tradução pelo engajamento da Academia, da Crítica Literária e do Mercado Editorial. Belas Infiéis, v. 6, n. 2, pp. 21-32.

CARIBÉ, Y. J. A. (2019). Do surgimento do novel inglês à publicação de Nutshell (2016) de Ian McEwan: atualizações do romance nas literaturas de língua inglesa. Revell, v. 3, n. 23, pp. 349-373.

EVEN-ZOHAR, I. (2000). A posição da literatura traduzida dentro do polisistema literário, trad. Leandro de Ávila Braga. In: Revista Translatio, n. 3, pp. 03-10, 2012.

GRAIEB, C. (2016). 'Atlas de Nuvens' revela gênio fabulador de David Mitchell. Jornal Folha de S. Paulo. Sessão Ilustrada, Crítica. 22 nov. 2016. Disponível em: < https:// www 1.folha.uol.com.br/ilustrada/2016/11/1834285-atlas-de-nuvens-revela-geniofabulador-de-david-mitchell.shtml>. Acesso em: 28 fev. 2020. 
KLEIN, K. F. (2016). Crítica: "Atlas de Nuvens", de David Mitchell. Jornal O Globo. Sessão Cultura, Livros. 05 nov. 2016. Disponível em: < https://oglobo.globo. com/cultura/livros/critica-atlas-de-nuvens-de-david-mitchell-20413039>. Acesso em: 28 fev. 2020.

MCEWAN, I. (2001). Reparação, trad. Paulo Henriques Brito. São Paulo: Companhia das Letras.

MCEWAN, I. (2016). Enclausurado, trad. Jorio Dauster, 4. reimp. São Paulo: Companhia das Letras, 2016.

MILLER, B. K. (2015). Re-Construction Through Fragmentation: A Cosmodern Reading of David Mitchell's Cloud Atlas. 49f. Dissertação de Mestrado - East Tennessee State University, Johnson City (E.U.A.). Disponível em: < https://dc.etsu.edu/cgi/ viewcontent. cgi? article $=3880 \&$ context $=$ etd $>$. Acesso em: 28 fev. 2020 .

MITCHELL, D. (1999). Ghostwritten. 1. ed. Londres: Sceptre.

MITCHELL, D. (2004). Cloud Atlas, 1. ed. Londres: Sceptre.

MITCHELL, D. (2016). Atlas de Nuvens, 1. ed., trad. Paulo Henriques Britto. Rio de Janeiro: Companhia das Letras.

NOUSS, A. (2012). A tradução: no limiar, trad. Izabela Leal. In: ALEA, Rio de Janeiro, v. $14 / 1$, pp. $13-34$

PEREIRA, V. S. (2016). Ficção Científica encontra o Pós-Modernismo: Slipstream. Revista Em Tese, Belo Horizonte, v. 22, n. 3, pp. 245-262. Disponível em: <http://www. periodicos.letras.ufmg.br/index.php/emtese/article/view/11111/10707>. Acesso em: 12 jun. 2020.

SILVA, J. P. (2020). Atlas de Nuvens: Caminhos cruzados $-1^{\text {a }}$ parte. Jornal Mais Minas. Sessão Literatura. 16. Abril. 2020. Disponível em: <https://maisminas.org/ entretenimento/literatura/2018/10/20/atlas-de-nuvens-caminhos-cruzados $>$. Acesso em: 12 jun. 2020.

SOUZA, D. S. de. (2018). A subalternidade em Clould Atlas, de David Mitchell. 124f. Dissertação de Mestrado - Universidade Estadual Paulista Júlio de Mesquita Filho, Campus de São José do Rio Preto (SP, Brasil), 2018. Disponível em: < https://repositorio. unesp.br/handle/11449/152855 >. Acesso em: 28 fev. 2020. 
VON HOLDEFER, C. (2016). grande, mas não é Pynchon: Paulo Henriques Britto e a tradução de Atlas de Nuvens (entrevista concedida em 13. Ago. 2016). Disponível em: <https://www.camilavonholdefer.com/e-grande-mas-nao-e-pynchon-paulohenriques-britto-e-a-traducao-de-atlas-de-nuvens/>. Acesso em: 12 jun. 2020.

YUSTE FRÍAS, J. (2014). Paratextualidade e tradução: a Paratradução da literatura infantil e Juvenil. In: Cadernos de Tradução, Florianópolis, n. 34, pp. 09-60.

YUSTE FRÍAS, J. (2015). Paratraducción: la traducción de los márgenes, al margen de la traducción. In: DELTA, v. 31, n. 4, pp. 317-347.

Recebido: 18/6/2020

Aceito: 17/7/2020

Publicado: 24/7/2020 